\title{
LA DIMENSIÓN DIALOGÍSTICA DE LA CARTA: UNA LECTURA DEL PACTO EPISTOLAR EN LA CORRESPONDENCIA DE ANTOINE DE SAINT-EXUPÉRY
}

\author{
María del Pilar Saiz Cerreda \\ Universidad de Navarra
}

\begin{abstract}
RESUMEN: En este artículo voy a mostrar cómo la función del pacto epistolar cohesiona la correspondencia íntima familiar de Antoine de Saint-Exupéry en el nivel pragmático a través de una cláusula precisa como es la dimensión dialogística del intercambio epistolar. Como el pacto es un contrato en movimiento entre las instancias enunciativas necesita la presencia activa de las dos, no sólo del epistológrafo. El pacto es cumplido en la medida en que el destinatario responde a las cartas que el autor le envía. Cuanto más constantes y regulares sean las respuestas, más se asemejará el intercambio a un diálogo. El autor va creando esta dimensión cuando hace de cada carta el espacio en el que los diálogos se dejan oír gracias a la inclusión de "concise analyses", "interior dialogue" y "fantasy dialogue", siguiendo a J. G. Altman. El diálogo epistolar deja de ser un lugar común en las cartas de este autor.
\end{abstract}

RÉSUMÉ: Le présent article tient à montrer comment la fonction du pacte épistolaire structure la correspondance intime familiale d'Antoine de Saint-Exupéry au niveau pragmatique à travers une clause précise, telle la dimension dialogistique de l'échange épistolaire. Comme le pacte est un contrat en mouvement entre les instances énonciatives, il a besoin de la présence active des deux ensemble. Le pacte est accompli dans la mesure où le destinataire répond aux lettres que l'auteur lui envoie. Plus constantes et régulières seront les réponses, plus l'échange se ressemblera à un dialogue. L'auteur crée cette dimension lorsqu'il fait de chaque lettre l'espace où les dialogues se laissent entendre grâce à l'inclusion de "concise analyses", "interior dialogue" et "fantasy dialogue", d'après J. G. Altman. Le dialogue épistolaire n'est plus donc un lieu commun dans les lettres de cet auteur.

PALABRAS CLAVE: Carta; pacto epistolar; proceso de seducción; "concise analyse"; "interior dialogue"; "fantasy dialogue".

MOTS-CLÉS: lettre; pacte épistolaire; procès de séduction; "concise analyse"; "interior dialogue"; "fantasy dialogue".

Una de las características que definen al hombre como tal, generalizando, es su dimensión relacional o comunicativa: el hombre necesita comunicarse. No tenemos más que echar una mirada a la historia y estudiar la función del lenguaje como medio de comunicación necesario para la relación. Lo mismo sucede con el papel de la escritura. Remontándonos en el tiempo, desde su aparición en las civilizaciones 
más antiguas, como la acadia o la sumeria, la escritura se ha contemplado como un medio de comunicación con fines variados, uno de los cuales permitía poner en contacto o relación a personas ausentes. Es el nacimiento de los intercambios epistolares. Con el tiempo, se fue teniendo cada vez más presente esta dimensión comunicativa de la carta.

De hecho, un rápido repaso sobre las distintas definiciones de la misma, nos muestra cómo el componente comunicativo es el más destacado. Por esta razón no nos extraña que a lo largo de la tradición literaria los epistológrafos insistan en la semejanza de la correspondencia con la conversación o el diálogo, convirtiéndose en signo característico del espacio epistolar. Así por ejemplo, son muy significativas las definiciones de algunos clásicos de la antigüedad como es el caso de Artemón, editor de las cartas de Aristóteles, según el cual la carta es una parte de un diálogo. O bien, las de Cicerón y Quintiliano, para quienes la carta es "sermo absentis ad absentem". Para Séneca, con la carta recibida es como si se oyera al ausente y con la carta enviada es como si se le hablara. Erasmo, basándose precisamente en estas fórmulas de los clásicos, recuerda en su De conscribendis epistolis, que "est enim epistola absentium amicorum quasi mutuus sermo"'. A lo largo de los siglos siguientes las definiciones han insistido de una manera o de otra en este aspecto. Es el caso de Antoine Furetière, en el siglo XVII o, en nuestros días, Marie-Claire Grassi. Para el primero, "La lettre se dit d'un écrit qu'on envoie à un absent pour lui faire entendre sa pensée"2. Grassi, por su parte, comenta que la carta es "un acte de communication à distance", para después insistir: "La lettre est un texte inscrit dans un acte de communication"3. Del mismo modo, Émile Michel Cioran insiste en esta dimensión afirmando que la carta es una conversación con un ausente y constituye un acontecimiento capital de la soledad ${ }^{4}$.

En el contexto de la crítica hispánica Miriam Álvarez ha puesto el acento en este aspecto de suma importancia. Para ella, la carta es "una forma de interacción social, que parte de una situación comunicativa muy especial: uno de los interlocutores no está presente. Se trata, por tanto, de una "conversación" retardada, pues el yo que escribe una carta, espera, en la mayoría de los casos, una contestación"5. En esta línea, Francisco López Estrada opina que "Al unir las gentes entre sí las ausencias, las cartas van dejando el testimonio universal de este afán de relacionarse los unos con los otros que han sentido siempre los hombres. Porque la carta lleva siempre consigo un anhelo de comunicación, cifrado en la más sensible unidad

1. Cit. por A. Soria Olmedo, "Dos voces a nivel", en P. Salinas; J. Guillén, Correspondencia (1923-1951), Barcelona: Tusquets, 1992, pp. 9-36.

2. Cit. por M-C. Grassi, Lire l'épistolaire, Paris: DUNOD, 1998, p. 2.

3. Ibid., pp. X, 151.

4. É. M. Cioran, Oeuvres, Paris: Gallimard, 1995.

5. M. Álvarez, Tipos de escrito III: Epistolar, administrativo y jurídico, Madrid: Arco / Libros, S.L., 1997, p. 11. 
histórica: el hombre. Pues hay que escribir a alguien, comunicarse con otro"6. Si la forma más común de relación entre los hombres viene representada por la palabra hablada y por extensión, por el diálogo, entonces el intercambio epistolar se caracteriza por su dimensión dialogística que queda así destacada en un primer plano.

El objetivo de este artículo apunta a establecer el análisis de esta dimensión dialogística propia de un intercambio epistolar, en general, y de cada carta, en particular, en el seno de una correspondencia concreta, la de Antoine de SaintExupéry. Se trata de una aproximación no tenida en cuenta hasta ahora, por lo que representa un asunto novedoso en el seno de los estudios consagrados a la obra del autor. Las cartas en las que nos vamos a basar constituyen lo que podríamos nombrar la correspondencia íntima familiar del autor, esto es, la mantenida con sus más allegados, familiares y amigos y que ha sido publicada por Éditions Gallimard.

Ahora bien, esta dimensión dialogística que contribuye a crear el espacio epistolar, podría no pasar de ser un simple "topoi" de la geografía epistolar y sin embargo se erige en condición impuesta por los epistológrafos a la hora de llevar a cabo el acto epistolar. Dicha dimensión no podría ser tenida en cuenta sin la existencia de un pacto previo entre los actantes, pacto que se convierte en garante y función dominante que estructura la escritura y el intercambio epistolares en su misma esencia. Nos estamos refiriendo al pacto epistolar, noción derivada del pacto autobiográfico de Philippe Lejeune. Aunque Lejeune no habla de pacto epistolar, sin embargo al definir el autobiográfico podemos asentar las bases del epistolar, pues comparte en esencia esta definición, a la que es preciso añadir alguna particularidad más específica. El pacto autobiográfico es, pues, tal como Lejeune lo define, "un contrat d'identité qui est scellé par le nom propre"7, pero para tener un pacto epistolar hay que sumar al autobiográfico una característica singular, el epistolar es un pacto en acción, esto es, dirigido a un destinatario que tiene que suscribirlo definitivamente a través de la respuesta. Entonces el pacto permite al autor desplegar una estrategia de seducción sobre el destinatario que apunta a la consecución de la respuesta y que tiene manifestaciones en los distintos niveles discursivos, pragmático, semántico y textual. De esta forma la carta entera se convierte, siguiendo a Gérard Genette, en "lieu privilégié d'une pragmatique et d'une estratégie, d'une action sur le public au service, bien ou mal compris et accompli, d'un meilleur accueil du texte et d'une lecture plus pertinente - plus pertinente, s'entend, aux yeux de l'auteur et de ses alliés"8.

6. F. López Estrada, Antología de Epístolas, Barcelona: Editorial Labor, 1961, p. 3.

7. P. Lejeune, Le pacte autobiographique, Paris: Éditions du Seuil, 1996, p. 33.

8. G. Genette, Seuils, Paris: Éditions du Seuil, 1987, p. 8. 
El punto de partida de la escritura epistolar está marcado, siguiendo la terminología empleada por Genette, por una "situation d'énonciation"9 particular, marcada por la ausencia de los corresponsales, debido a la distancia que los separa. Es decir, que la única posibilidad de contacto la da precisamente la carta. Siendo así las cosas, es lógico valorar en su justa medida el papel de los actantes de la comunicación, emisor y receptor, además de tener presente la propia situación comunicativa originada por la distancia. Esto nos pone de relieve la importancia del nivel pragmático, pues es ahí donde se van a asentar las bases del pacto que van a suscribir epistológrafo y destinatario de la carta. No en vano, este nivel es el que, como reza el Diccionario de la Lengua Española, "estudia el lenguaje en su relación con los usuarios y las circunstancias de la comunicación"10.

La situación de comunicación de emisor y receptor, en ausencia, es en extremo importante, pues es la desencadenante del proceso epistolar y la razón del despliegue del proceso de seducción o "panoplia de seducción", en expresión de Andrés Soria Olmedo ${ }^{11}$. En efecto, si el emisor quiere seducir necesita enviar la carta, poner en marcha el mecanismo epistolar. Por eso no podemos perder de vista que la carta se escribe para ser enviada y para establecer comunicación con el otro. El pacto epistolar adquiere su máxima expresión y se ratifica en la medida en que el acto de escritura epistolar por parte del autor es seguido por el acto de lectura de la carta por parte del destinatario y completado por el de la respuesta. El proceso comunicativo se reinicia en sentido contrario: el receptor pasa a ser emisor y el emisor receptor. Es el comienzo de un intercambio que, en especial el autor primero, el que ha desencadenado el proceso, va a procurar que sea más o menos constante, dado que es él el que apunta a conseguir el objetivo último del intercambio epistolar, que no es sino la abolición de la ausencia ${ }^{12}$. La estructura circular de la carta adquiere un peso de gran envergadura, hasta el punto de que la regularidad y constancia de las respuestas se convierten en cláusulas importantes que aseguran la realidad del pacto. La fluidez y frecuencia de las mismas son las que permiten hablar del diálogo epistolar como una cláusula más que representaría el exponente máximo o culminación del pacto epistolar. En la medida en que el intercambio es constante, los actantes parecen hacerse más presentes. De ahí procede la dimensión dialogística de un intercambio epistolar, que hace creer en la ilusión de una presencia que, mientras exista correspondencia, no será actual, real.

9. G. Genette, "Genres, types, modes", en Poétique, no 32, 1977, p. 389-421.

10. Diccionario de la Lengua Española. Real Academia Española, $22^{\mathrm{a}}$ edición, Madrid: EspasaCalpe, 2001, p. 1816.

11. A. Soria Olmedo, loc. cit., p. 15.

12. Los términos concretos en que el pacto se lleva a cabo dependen del epistológrafo y del destinatario concretos. La variabilidad es la nota dominante de cada pacto. Ahora bien, una vez establecidas las condiciones en que la correspondencia se va a llevar a cabo, deben ser respetadas las cláusulas del mismo por los artífices del intercambio, emisor y receptor. 
Detenerse en el estudio de la dimensión dialogística de la carta supone dos cosas: en primer lugar, observar cómo la carta trata de ser la mimesis de un diálogo que se realiza en el texto epistolar. Esto, a su vez, se puede crear con el juego del envío y la respuesta correspondiente del destinatario, o también, con la reproducción de diálogos en el interior de la carta. Y en segundo lugar, supone analizar el estilo hablado o rasgos de oralidad que contribuyen a crear la metáfora de la conversación epistolar; metáfora porque como explica Genette, no se puede olvidar que el destinatario "prend connaissance" d'une manière toujours différée"13. En este trabajo nos detendremos tan sólo en el primer aspecto, es decir, en la constatación de dicha reproducción de diálogos en el interior de la correspondencia a la que ya hemos aludido anteriormente.

Janet Gurkin Altman, gran estudiosa del género epistolar, habla de la existencia de una "chain of dialogue"14 en toda carta, o más precisamente en toda correspondencia. En cierto sentido equivale a lo que Catalin Mamali ha definido como "dialogue virtuel"15, en tanto cada carta de una correspondencia es potencialmente una parte de lo que se convertirá en un diálogo escrito. El pacto epistolar hace que esto sea posible, pues como hemos dicho, "la panoplia de seducción" es lo que se despliega con un intercambio. Y ésta se revela en toda su fuerza desde el momento en que la primera instancia enunciativa se dirige a la segunda para intentar atraerla con vistas a obtener la respuesta deseada.

Pero Altman entiende esta realidad de manera más amplia. En efecto, la dimensión dialogística de la carta se observa en primer lugar, según ella y de acuerdo con Mamali, en tanto que la conversación es el objetivo de las cartas en el seno de una correspondencia gracias al juego carta-respuesta que produce este efecto de diálogo. En segundo lugar, el diálogo no sólo es una imagen empleada para hablar del efecto que produce la presencia de la respuesta. La realidad del diálogo en la carta va más allá, pues ésta es además el espacio propio en que los diálogos se dejan oír. Si bien Altman los ha considerado dentro del campo de la carta ficcional y por tanto, en el interior de la literatura epistolar, existen aspectos susceptibles de ser aplicados en igual medida al análisis de una correspondencia real.

Los diálogos que una carta puede reproducir, siguiendo sus explicaciones, pueden ser de muy distintos tipos: los "concise analyses"16, serían aquellos que se aproximarían en mayor grado a la reproducción exacta de un diálogo oído. Otro

13. G. Genette, Seuils, Paris: Éditions du Seuil, 1987, p. 374.

14. J.G. Altman, Epistolarity. Approaches to a Form, Columbus: Ohio State University Press, 1982, p. 187.

15. C. Mamali, "Correspondance et dialogue virtuel du niveau individuel au niveau sociétal", en La lettre à la croisée de l'individuel et du social, Paris: Kimé, 1994, pp. 179-185.

16. J.G. Altman, loc. cit., p. 113. 
tipo de diálogo, posiblemente más corriente, que se puede encontrar en el interior del discurso epistolar es lo que ella denomina "interior dialogue", que Benoît Melançon, otro de los estudiosos del género epistolar, define como "pseudo-dialogues"17. Éstos pueden venir dados a través de referencias a párrafos o palabras de las cartas recibidas, o a través de paráfrasis de conversaciones o cartas, con lo que la voz del destinatario se haría más presente en el interior de la carta. Por último, también podría darse el caso de que fueran imaginarios o "fantasy dialogue"18. Entraríamos entonces en el campo de la ficción ya que el epistológrafo crearía en su discurso un diálogo con una imagen a través de componentes ficticios e históricos.

Veámoslo ejemplificado en la correspondencia de Saint-Exupéry. A él no le basta con escribir una carta. El deseo de respuesta va implícito en su discurso epistolar. Más aún, las referencias concretas a la respuesta son constantes. Quiere que la carta que él escribe a su corresponsal tenga efectos retroactivos para así dar cauce a una correspondencia estable. Por esta razón podemos decir que sus cartas tienen una clara dimensión dialogística, constituyen una auténtica "chain of dialogue" en tanto consiguen ese efecto de diálogo. Insiste una y otra vez en ello, como podemos comprobar, en esta carta a su amiga Renée de Saussine, en que le dice explícitamente que las cartas que se escriben ambos suponen "les seules conversations que j'ai avec vous"19. De esta manera, la ausencia propia de la situación enunciativa se metaforiza con el intercambio epistolar. El proceso de seducción desplegado en el instante de la escritura obtiene la recompensa deseada por Saint-Exupéry: abolir las distancias que le separan de su corresponsal.

Además, la dimensión dialogística de sus cartas se puede comprobar también por la existencia de los distintos tipos de diálogo que, siguiendo a Altman, reproduce en su escritura epistolar: "concise analyses", "interior dialogues" y "fantasy dialogues". Entresacamos algunos de los que consideramos más relevantes. En primer lugar, diálogos literales. Siguiendo el esquema de Altman, los "concise analyses" serían las reproducciones de los diálogos oídos extrapolados al texto. La diferencia con los "interior dialogues" estriba en el hecho de que los "concise analyses" no reproducen citas de pequeños fragmentos de la carta a la que tiene que dar respuesta, ni palabras sueltas de cartas anteriores, ni siquiera frases aisladas de alguna conversación escuchada con anterioridad, sino que reproducen extensos diálogos en el discurso epistolar. El diálogo se convierte en objeto textual. Existe un caso muy concreto en la correspondencia de Saint-Exupéry que responde a este modelo. Se trata de una carta escrita a su amigo Louis de Bonnevie en la que, en 1918 y mientras estaba en

17. B. Melançon, Diderot épistolier. Contribution à une poétique de la lettre familière au XVIIIe siècle, Montréal: Fides, 1996, p. 255.

18. J.G. Altman, loc. cit., p. 139.

19. A. de Saint-Exupéry, Oeuvres complètes I, Paris: Gallimard, Bibliothèque de la Pléiade, 1994, p. 801. 
París en pleno ataque alemán durante la Primera Guerra Mundial, le cuenta los momentos tan intensos vividos con ocasión del bombardeo alemán. El relato preciso de los acontecimientos le permite introducir las conversaciones mantenidas con sus compañeros en el instituto Saint-Louis, donde preparaba los exámenes de ingreso a la Escuela de Ingenieros. Dichas conversaciones constituyen una de las características fundamentales de esta carta. Debido a la extensión de la misma, citamos tan sólo fragmentos de los diálogos:

- Dis-donc, c'est les boches?

- T'as qu'à écouter! ...

- C'est le canon!

- Hé oui!

- Tu vas en quinzième étude?

- Faut bien.

- Mais on ne verra rien!

- C'est vrai.

- Moi, je veux voir!

- Moi aussi.

- Alors, on monte au "graphto"? ...

- Ça colle, mais si on est repéré, c'est douze heure de colle ou la porte...

- Tant pis, je risque ça!

- Moi aussi. ${ }^{20}$

Prosigue un poco más adelante, una vez que han conseguido eludir a los vigilantes, instalados en la sala superior, de grandes ventanales, mientras observa los bombardeos en primera fila:

- Entends-tu?

- Oui, ils vont sur nous!

- Ce sont les boches, ils n'ont pas de feu rouge.

- Oui.

- Les avions de chasse les suivent... Oh, regarde! ...

- Il y a du grabuge dans Paris, y a sûrement des tués!

- Oh oui! ....

Sin duda ninguna, la atención del destinatario es captada con la transcripción de estos diálogos, siempre reforzados por los rasgos propios del estilo hablado. Además hay que añadir que el efecto de realismo que se consigue con la reproducción de los diálogos es mucho mayor que el conseguido a través del relato

20. Ibid., p. 838.

21. Ibid., p. 839 
pasado de los acontecimientos y así puede conmover al receptor. Esto queda patente en la siguiente carta que escribe a Pierre Chevrier, en la que quiere mostrar el dolor que siente tras la ruptura de una vértebra, posibilidad que no era admitida por su amigo el doctor Pélissier. El diálogo se establece entre Saint-Exupéry y otro médico, radiólogo esta vez, que mantiene una opinión contraria a la del doctor Pélissier:

- Mais vous êtes dément d'être debout! Vous avez une fracture transversale de la cinquième lombaire, avec en plus, léger écrasement vertical et bavure osseuse. De plus, toute la vertèbre est déportée de quelques millimètres vers la gauche!

- Ah! Bon.

- C'est sérieux, une vertèbre cassée! C'est trois mois de lit! Vous allez vous estropier pour la vie...

- Ah, bon!

- Mais nom de Dieu, vous ne sentez donc pas que vous avez une vertèbre cassée?

- Oh! si! $!^{22}$

En segundo lugar, podemos observar igualmente en esta correspondencia diálogos intradiscursivos. Acabamos de comprobar cómo en el interior del diálogo que es la correspondencia existen unos diálogos que conforman el desarrollo diegético epistolar. Pero en las cartas de Saint-Exupéry existe otro tipo de diálogos que no constituye el objeto central de la carta, sino un motivo más en el interior del discurso y por tanto, tales diálogos no son pieza fundamental de éste. Buscan perseguir el efecto de realidad, la creación de un presente intemporal epistolar para poder mantener la atención del destinatario, razón por la cual reproducen parcialmente alguna conversación del exterior o fragmentos o palabras de la carta que el destinatario le ha enviado a Saint-Exupéry como respuesta. Se trata de los "interior dialogues" de Altman. Son muy numerosos los casos de cartas de SaintExupéry que nos ofrecen pequeños bosquejos de los mismos.

En esta carta dirigida a Chevrier, nuestro autor, de vuelta de una misión aérea durante el inicio de la Segunda Guerra Mundial, para ilustrar las extremas condiciones atmosféricas en que ha realizado el vuelo, reproduce esta corta conversación con alguno de los pilotos:

- Quelle température?

- Moins $51^{\circ}$.

22. A. de Saint-Exupéry, Oeuvres complètes II, Paris: Gallimard, Bibliothèque de la Pléiade, 1999, p. 956. 
- Tu n'as pas dû avoir bien chaud?

- Si, mais rien de désagréable. Tu m'avais dit que l'oxygène chaud brûlait le nez, et mon nez n'était bien à l'aise. Quant aux chaussons..... ${ }^{23}$

Muchas veces la relación de una conversación, ya sea el propio Saint-Exupéry uno de los actantes de la misma (y por tanto, narrador homodiegético), ya sea oyente de otros interlocutores (y por tanto, narrador heterodiegético), le sirve como punto de partida para iniciar un tema, o para contar en la carta a su corresponsal algo relacionado con el motivo de ese corto diálogo. De esta manera, puede captar la atención con más eficacia, al presentarlo en un estilo directo. Así, en una carta a su prima Yvonne de Lestrange, reproduce esta breve conversación que acaba de escuchar en el tren. Es el punto de partida para escribirle sobre el egoísmo reinante en la época - finales de los años 20 -, sobre todo en determinados ambientes:

- Il est mort tout à coup, comme ça, c'est extraordinaire...

- Mais non, c'est une mort subite.

- Il était allé fumer une cigarette à l'entracte, comme tout le monde...

- Oh! C'est bien vrai, tout le monde le fait!... ${ }^{24}$

Igualmente, podemos encontrar en las cartas palabras o frases que insinúan cuestiones abordadas en cartas anteriores enviadas por los otros corresponsales, con lo que la práctica dialogística parece tener continuidad. Es lo que en términos lingüísticos se conoce como diafonía. Catherine Kerbrat-Orecchioni, que se basa en las teorías de Eddy Roulet sobre esta cuestión, explica que la diafonía consiste en "reprendre et réinterpréter dans son propre discours la parole du destinataire, pour mieux enchaîner sur celle-ci"25. Esto mismo constituye la "interacción" epistolar ${ }^{26}$. Destacamos algunos ejemplos - son muy variados - en los que de forma patente se deja entrever la voz del interlocutor, del destinatario, por los comentarios o respuestas suscitados en nuestro autor. Los encontramos de forma especial en las cartas a su madre, que es con quien mantenía un intercambio más regular, urgente, periódico y constante.

Las palabras con las que retoma la práctica epistolar pueden adoptar tonos diversos en función del empleado por su corresponsal. Unas veces son palabras que sirven como respuesta a una pregunta formulada en la carta anterior. A vuelta

23. Ibid., p. 940.

24. Ibid., p. 855.

25. C. Kerbrat-Orecchioni, "L'intéraction épistolaire", La lettre entre réel et fiction, Paris: SEDES, 1998, pp. 15-36.

26. Este término ha sido acuñado por Kerbrat-Orecchioni. 
de correo, Saint-Exupéry le contesta a su madre. Retoma y parafrasea las palabras que ella le había dirigido: "Vous me dîtes de donner des détails sur mon existence"27. Otras veces puede reflejar la preocupación por una noticia que le afecta. Lo vemos en la respuesta a una noticia que su madre le da relativa a su estado de salud. Por eso exclama: "Je suis désespéré de vous sentir malade"28. También puede ser la justificación o defensa ante un reproche que se le hace: "Mais je vous ai écrit une lettre de presque dix pages!"29. En otras ocasiones se limita a reproducir algunas palabras para corroborar un comentario dado en una carta anterior: "Vous m'avez écrit une si douce lettre, maman, c'est vrai que je n'ai plus été moi-même pendant longtemps"30. Las referencias a noticias, acontecimientos, sentimientos o informaciones transmitidos en otras cartas son constantes y permiten abolir la distancia en mayor medida. En consecuencia, la ausencia de las instancias epistolares parece difuminarse.

Las cortas réplicas, las reproducciones de breves palabras de cartas anteriores, pueden, en igual medida, ceder su puesto a largas citas literales de cartas recibidas, demostrando una vez más la continuidad de la correspondencia y la apariencia de diálogo en consecuencia. El pacto está sellado y asegurado. Un ejemplo muy gráfico al respecto lo encontramos en esta carta a su madre en la que, tomando como base los comentarios expresados por uno de sus amigos en una carta, los transcribe, convirtiéndose en el punto de partida del asunto que va a tratar:

Il m'écrit:

" ... J'ai bien compris tout ce que tu m'as dit. Aussi bien ce que tu m'as appris que ce que je ressentais confusément et que tu éclairais en moi parce que tu sais penser, toi, et exprimer ta pensée clairement et simplement, etc...

... En pensant au bien que tu m'as fait et aux progrès que j'ai faits grâce à toi je... etc.

... L'autre jour encore en te parlant, à plusieurs reprises, j'ai senti combien de travail j'avais à fournir si je voulais me hausser et voir le monde de ton plan... etc...

... Si tu savais combien je t'admire, aussi bien pour le travail que tu as fourni que pour le résultat... etc." ${ }^{31}$

27. A. de Saint-Exupéry, Oeuvres complètes I, Paris: Gallimard, Bibliothèque de la Pléiade, 1994, p. 677.

28. Ibid., p. 681.

29. Ibid., p. 704.

30. Ibid., p. 737.

31. Ibid., p. 743. 
Así pues, estos diálogos internos jalonan la correspondencia de Saint-Exupéry. La carta, gracias al pacto suscrito con los destinatarios, adquiere esa dimensión dialogística, no sólo porque la reciprocidad en las respuestas, el juego de la pregunta y la respuesta, permite dar la imagen de una conversación, sino porque la propia carta, en su misma estructura interna, tiene componentes que hacen más real esta dimensión a través de las citas de palabras, párrafos o a través de reproducciones parciales de diálogos en su interior. Al mismo tiempo, el hecho de que esté planteada así, con esa estructura, hace que la carta pueda tener continuación. Por eso no es extraño que Saint-Exupéry recurra a este procedimiento en su intento de estrechar el contacto con su corresponsal y de abolir la ausencia y distancia física que le separa de él.

Por último, en la correspondencia de este autor encontramos algunos casos de diálogos ficticios, o lo que es lo mismo, muestras de lo que Altman denomina "fantasy dialogue", que hacen pensar en el fracaso del pacto. Sólo este tipo de diálogo, que ya no es tal, es posible cuando el corresponsal no da continuación a las cartas recibidas, en especial, cuando las condiciones del pacto en lo relativo a regularidad y frecuencia, no son respetadas por parte de alguna de las instancias enunciativas. Entonces, en ausencia de un interlocutor verdadero, el epistológrafo crea una imagen de su corresponsal a su medida, proyectando en ella una serie de características, rasgos y virtudes de que carece el destinatario real, según el autor. A esta imagen es a la que el autor dirige ahora sus cartas. Por tanto, aunque la carta tenga un receptor real, el destinatario implícito, como expresaríamos en términos narratológicos, es otro distinto, sin referente extratextual. Con esta imagen entonces, es más fácil que la conversación epistolar se pueda llevar a cabo ${ }^{32}$.

Un ejemplo que se adecua a lo explicado por Altman lo encontramos en una carta de Saint-Exupéry a su amiga Renée. Tras el enfado de aquél ante la falta de respuesta continuada, aspecto en el que Renée reincidía una y otra vez, se decide a fabricar una imagen de una corresponsal que se adapte mejor a las condiciones epistolares que él exige. La imagen está dotada de virtudes, valores y características que a Saint-Exupéry le hubiera gustado ver en su amiga. De igual manera, el cambio operado en su amiga, esto es, en la imagen creada por él, repercute en sí mismo que se encuentra a su vez transformado. Por esa razón se siente a gusto "hablándole",

32. Para algunos autores, como A. Jaubert, éste es un peligro latente en toda correspondencia, derivado del hecho de que la escritura de una carta se realiza en ausencia. Entonces, según él, la carta "n'a pas le rythme de la conversation, et le scripteur, libéré de la présence physique de l'Autre, des interruptions, des mimiques, ou simplement de la nécessité de "passer" la parole, peut, à loisir, projeter un destinataire idéal, lecteur sur mesure des complaisances introspectives, narratives parfois, et de toutes les effusions" (cit. por M.-F. Chanfrault-Duchet, "Lettres d'adolescents en détresse: énonciation du moi et représentations sociales", La lettre à la croisée de l'individuel et du social, Paris: Kimé, 1994, pp. 186-193). 
como él mismo dice. Gracias a todas estas transformaciones consigue crear una atmósfera apropiada para mantener una conversación en la intimidad de la amistad, deteniendo el tiempo en un presente del que parecen ausentarse todas las circunstancias externas y los aspectos negativos. Para la construcción de ese presente irreal, extrapola uno de los contextos que más le gustan, y que los dos amigos compartían: las veladas musicales. Es decir la autorrepresentación epistolar es imaginada y recreada por el autor. Parece exorcizar la ausencia que siente más presente desde que las cláusulas del pacto no han sido respetadas por Renée. Si no es posible hacerlo por vía del diálogo epistolar, habrá que recurrir a otros medios:

Et je viens de m'asseoir près de vous ce que sans doute vous ne permettez pas non plus. Ce qui vous agace. Mais si vous saviez comme je m'en moque. Car je vous fabrique ce soir à mon gré et si vous saviez comme vous êtes gentille. Au fond ce sont les seules conversations que j'ai avec vous. Celle que j'invente en moi-même. Et vous êtes d'une patience. Et d'une intelligence: vous comprenez tout. Et moi je deviens bavard: ça c'est merveilleux. Quelle revanche je prends avec mon amie inventée.

Car c'est peut-être parce que je vous invente que je tiens tellement à vous. Parfois pourtant vous cadrez avec votre image. En tout cas vous l'alimentez. Et votre après-midi de musique donne beaucoup de vie à cette amie que j'ai ce soir. Vous êtes un peu mêlée d'Offenbach. Vous avez la couleur des abat-jour. Ne vous plaignez pas. Ce n'est pas mal. Et puis cela ne vous regarde pas". ${ }^{33}$

Sin embargo, Saint-Exupéry es consciente de que estas conversaciones no son tales, pues desde el momento en que son fabricadas por la imaginación se convierten en diálogos imaginarios o ficticios, lo que supone una ruptura del pacto tal como había sido establecido por las dos instancias enunciativas epistolares ${ }^{34}$. Es cierto que al proyectar sus deseos sobre cómo le gustaría que fuese la relación epistolar con su amiga, está llamando su atención. La carta funciona como un reproche continuo por el que busca la reacción en el destinatario a pesar del enfado mostrado. Con la manifestación de las carencias en esa relación epistolar y de la proyección de sus deseos, está ofreciendo a su destinataria la posibilidad de retomar la relación epistolar tal como el autor pretende. Pero al mismo tiempo, esta carta nos hace considerar que estos diálogos son posibles por el poder de la escritura y por el poder de la ausencia

33. A. de Saint-Exupéry, loc. cit., p. 801.

34. En este caso, el de los diálogos ficticios, que son monólogos, en realidad, las cartas se asemejarían a la definición que Bernard Dupriez daba de las mismas: "Monologue du signataire assumant seul un dialogue avec le destinataire, par écrit" (B. Dupriez, Gradus. Les procédés littéraires, Paris: Union générale d'Éditions, 1984, p. 274). 
que actúan desde los primeros instantes. Es necesario por tanto, volver a recuperar las condiciones del pacto, si la dimensión dialogística es lo que quiere prevalecer, como forma más apropiada para reducir la impresión de lejanía siempre presente y favorecer la ilusión de la presencia.

Ahora bien, tales diálogos ficticios, en los que la realidad referencial se aleja, tanto en lo que concierne al contexto de enunciación, en el que el componente imaginativo juega una gran baza, como en lo que concierne a las personas epistolares, estarían más próximos de la prosopopeya, según las explicaciones de Paul de Man. De la misma manera que considera que la autobiografía es la extensión de esta figura retórica, que consiste en dotar a un personaje de voz o cara a través de los medios lingüísticos, a la correspondencia epistolar puede aplicarse este mismo fenómeno en el último caso. En efecto, esta figura permite poner voz a los ausentes, como explica Bernard Dupriez, para así "les faire agir, parler, répondre" ${ }^{35}$. Por un lado, las instancias enunciativas se pueden considerar casi personajes pues la imaginación del autor ha ejercido todo su poder al embellecerlas. Por otra parte, el autor imagina diálogos posibles con su corresponsal. Por eso Saint-Exupéry sólo recurre a este procedimiento en momentos extremos, para recuperar el pacto y siempre con la idea de que los intercambios epistolares tengan una continuidad.

En efecto, cuando las claúsulas del pacto se rompen, en el caso de la correspondencia de Saint-Exupéry, con frecuencia por la negligencia del destinatario que no considera el pacto como algo esencial, el diálogo pretendido con aquél sufre una transformación. Entonces la solución es proyectar esta conversación sobre una imagen inventada, como un diálogo de ficción, ya que no corresponde a la realidad del destinatario. Pero la consecuencia que se deriva de ello ofrece un resultado distinto al de la conversación. La carta se convierte en verdadero monólogo, ya que la reciprocidad no existe. Todos los recursos empleados para atraer al destinatario parecen perder su poder de persuasión. Las palabras vuelven a Saint-Exupéry, el diálogo se convierte en monólogo por mucho que la carta sea dirigida a otra persona. Es lo que ocurre de nuevo, en la correspondencia con Renée. Como no cumple el pacto tal como han acordado, se pueden observar aquí todas las posibilidades y alternativas ante el no cumplimiento de las cláusulas del mismo. Por eso, Saint-Exupéry considera alguna de las cartas a ella dirigidas como verdaderos monólogos en los que se habla a sí mismo. En dos ocasiones hace una breve reflexión a este respecto. Las dos cartas están escritas en el mismo lapso de tiempo: en el otoño de 1926. Y las dos cartas fueron recibidas por Renée. En la primera de ellas, con gran enfado, le dice: "Voilà. Tant pis pour vous, cette lettre. D'ailleurs elle n'est pas adressée à vous. J'ai bien

35. Ibid., p. 364. Además de dar voz a los ausentes con esta figura se puede poner voz a "les morts, les êtres surnaturels, ou même les êtres inanimés". 
le droit de faire la conversation avec moi-même"36. En la segunda carta, sin embargo, aun mostrando gran indignación, hace unas reflexiones más detalladas en las que insiste en el fracaso del pacto y la alternativa que le queda:

Et je ne sais pas bien pourquoi j'écris. J'ai grand besoin d'une amitié à qui confier les petites choses qui m'arrivent. Avec qui partager. Je ne sais plus pourquoi je vous choisis. Vous êtes si étrangère. Mon papier me renvoie mes phrases. Je ne puis plus imaginer le visage penché qui lit, être généreux de mon soleil, de mes petits gâteaux et de mes rêves. J'écris une lettre tout doucement, pour réveiller, sans trop y croire. Je m'écris peut-être à moi-même". ${ }^{37}$

Saint-Exupéry nos hace tomar conciencia de la versatilidad de la carta. Orientada por naturaleza a la comunicación, la precariedad del pacto en este último caso ante la dilación de la respuesta, nos revela otra de sus posibilidades, la de dirigirse a sí mismo. Pero hay que partir de una condición necesaria para que esto se lleve a efecto, como explica Haroche-Bouzinac, "la conscience d'un échec de la communication"38, como consecuencia de la ruptura del pacto. Entonces, del discurso epistolar se extrae el propio reflejo del autor que se convierte, como dice Pedro Salinas, en "Narciso involuntario"39. Involuntario por una razón, porque su deseo de comunicación no tiene continuidad en el destinatario, lo que le obliga a volverse hacia sí mismo, a replegarse sobre sí. Sólo puede ver el reflejo de su yo $^{40}$.

En consecuencia, el diálogo o la conversación no representan un dato anecdótico del espacio epistolar, como demuestran las cartas de Saint-Exupéry. Se trata de una dimensión que imprime su marca a toda la correspondencia en general y a cada carta, conversación con un ausente, según la tradicional definición, en particular, convirtiéndose en una cláusula importante del pacto epistolar que el autor establece con el destinatario. Pero para que el diálogo epistolar se convierta en cláusula, es preciso que el autor dote a cada una de sus cartas de esta dimensión conversacional,

36. A. de Saint-Exupéry, loc. cit., p. 802.

37. Ibid., p. 807.

38. G. Haroche-Bouzinac, L'épistolaire, Paris: Hachette, 1995, p. 95.

39. P. Salinas, "El defensor (1948). 1. Defensa de la Carta Misiva y de la correspondencia epistolar", Ensayos completos II, ed. de Solitas Salinas de Marichal, Madrid: Taurus, 1981, pp. 217-293.

40. Hay sin embargo correspondencias que desde el mismo inicio han estado abocadas al fracaso de la comunicación. Es el caso de las cartas entre Kafka y Milena. Para Kafka, tal como ha estudiado Vincent Kaufman, la correspondencia con ella mantenida sería una especie de "commerce avec les fantômes", tal como él mismo lo define, pues no estaba orientada en ningún momento a la comunicación. El hecho de estar dirigida a esta persona es para él el pretexto necesario para volverse hacia sí mismo, sin considerar en ningún momento la posibilidad de un proceso de persuasión o seducción del destinatario. Para Kafka no hay diálogo posible en las cartas (V. Kaufmann, L'équivoque épistolaire, Paris: Les Éditions de Minuit, 1990). 
no sólo a través del juego pregunta-respuesta que las cláusulas de urgencia, regularidad y constancia exigen y que producen la continuidad epistolar, sino teniendo en cuenta también que la carta es el espacio propio en que los diálogos se dejan oír. Por eso, en el discurso epistolar se pueden encontrar todos los tipos de diálogo posible: los "concise analyses" que reproducen una conversación escuchada; los "interior dialogue", que simplemente transcriben alguna frase de la misma, siendo ambos el punto de partida de un tema sobre el que el autor va a hablar; y los "fantasy dialogue", diálogo imposible o ficticio, que incluiría también los diálogos consigo mismo. De ahí que Melançon insista en la idea de que "le dialogue dans son acception la plus étendue se retrouve dans la correspondance"41. Por tanto, la dimensión conversacional de la carta ya no sólo es consecuencia del pacto suscrito sino que además forma parte de las condiciones del mismo. La carta entendida como diálogo se convierte en una cláusula más, como comprobamos en la correspondencia de Saint-Exupéry.

Pero además esta cláusula apunta a unos objetivos precisos. Como lo que el autor busca con la conversación epistolar es la abolición de las distancias entre los corresponsales y por ende, la desaparición del sentimiento de ausencia, los tipos de diálogo posibles en el interior de las mismas apuntan a este mismo fin. No en vano, el diálogo contribuye a crear el efecto de presencia que todo epistológrafo busca, como nos ha demostrado Saint-Exupéry. Por esta razón el recurso a la utilización de estos tipos de diálogo forma parte del proceso de seducción al destinatario, que de una forma u otra es interpelado para que se ponga en actitud de responder. El espacio epistolar queda así definido en función de esta dimensión o estructura dialogística.

\section{Bibliografía}

ALTMAN, J. G. Epistolarity. Approaches to a Form. Columbus: Ohio State University Press, 1982.

ÁLVAREZ, M. Tipos de escrito III: Epistolar, administrativo y jurídico. Madrid: Arco/Libros, 1997.

CHANFRAULT-DUCHET, M.-F. "Lettres d'adolescents en détresse: énonciation du moi et représentations sociales". En: BOSSIS, Mireille (Ed.). La lettre à la croisée de l'individuel et du social. Paris: Kimé, 1994, p. 186-193.

CIORAN, É. M. Oeuvres. Paris: Gallimard, 1995.

Diccionario de la Lengua Española. Real Academia Española. 22a edición. Madrid: Espasa-Calpe, 2001.

41. B. Melançon, loc. cit., p. 260. 
DUPRIEZ, B. Gradus. Les procédés littéraires (Dictionnaire). Paris: Union générale d'Éditions, 1984.

GENETTE, G. "Genres, types, modes". Poétique, 32, 1977, p. 389-421.

- Seuils. Paris: Éditions du Seuil, 1987.

GRASSI, M.-C. Lire l'épistolaire. Paris: DUNOD, 1998.

HAROCHE-BOUZINAC, G. L'épistolaire. Paris: Hachette, 1995.

KAUFMANN, V. L'équivoque épistolaire. Paris: Les Éditions de Minuit, 1990.

KERBRAT-ORECCHIONI, C. "L'intéraction épistolaire". En: SIESS, Jürgen (Ed.). La lettre entre réel et fiction. Paris: SEDES, 1998, p. 15-36.

LEJEUNE, P. Le pacte autobiographique. Paris: Éditions du Seuil, 1996.

LÓPEZ ESTRADA, F. Antología de Epístolas. Barcelona: Editorial Labor, 1961.

MAMALI, C. "Correspondance et dialogue virtuel du niveau individuel au niveau sociétal". En: BOSSIS, Mireille (Ed.). La lettre à la croisée de l'individuel et du social. Paris: Kimé, 1994, p. 179-185.

MELANÇON, B. Diderot épistolier. Contribution à une poétique de la lettre familière au XVIIIe siècle. Montréal: Fides, 1996.

DE SAINT-EXUPÉRY, A. Oeuvres complètes I. Paris: Gallimard, Bibliothèque de la Pléiade, 1994.

— Oeuvres complètes II. Paris: Gallimard, Bibliothèque de la Pléiade, 1999.

SALINAS, P. "El defensor (1948). 1. Defensa de la Carta Misiva y de la correspondencia epistolar". Ensayos completos II. Edición preparada por Solita Salinas de Marichal. Madrid: Taurus, 1981, p.217-293.

SORIA OLMEDO, A. "Dos voces a nivel". En: SALINAS, P. y J. GUILLÉN. Correspondencia (1923-1951). Barcelona: Tusquets, 1992, p. 9-36. 